\title{
Е.С. Палкина
}

\section{МЕТОДОЛОГИЧЕСКИЕ ПРИНЦИПЫ УПРАВЛЕНИЯ РЕАЛИЗАЦИЕЙ СТРАТЕГИИ РОСТА КОМПАНИИ}

\begin{abstract}
В настоящее время для России особенно важно решение актуальной проблемы обеспечения экономического роста отечественных компаний в долгосрочной перспективе. Научную основу внутрифирменного менеджмента реализации стратегии роста составляют методологические принципь управления. В статье излагаются классические и специфические принципы стратегического менеджмента, применимые для исследования области реализации стратегии роста компании, разработки и научного обоснования адекватного экономического механизма в соответствии с теоретическими положениями концепции системно-интегрированного управления. Использование предложенных автором принципов в деятельности отечественных компаний позволит им обеспечить эффективный экономический рост и высокую степень достижения стратегических иелей.

Ключевые слова:концепция системно-интегрированного управления, методология реализации стратегии, принциипы управления, стратегия роста, экономический рост.
\end{abstract}

В решении современной проблемы активизации экономического роста в России важная роль принадлежит управлению стратегическим развитием хозяйствующих субъектов в соответствии с общенациональным вектором форсированного инновационного экономического роста, что должно обеспечить высокие темпы социально-экономического развития страны. Фундаментальную научную основу системы внутрифирменного управления реализацией стратегии роста составляют методологические принципы. Вместе с тем, как показывают результаты проведенного исследования принципов стратегического управления, широко представленных в работах российских и зарубежных ученых, существующие исходные теоретические положения применимы главным образом для формирования стратегии компании либо имеют общий характер, т.е. распространяют свое действие на стратегический менеджмент в целом [1-7]. Вместе с тем вопросы влияния вида стратегии на специфику и приоритеты управления реализацией стратегии развития компании, вопросы координации цели роста организации с другими стратегическими установками не нашли должного отражения и обобщения в научной литературе.

Основываясь на результатах исследования различных точек зрения по данному вопросу, традиционные принципы стратегического менеджмента предлагается дополнить и развить с учетом сферы их приложения и теоретико-методологических положений концепции системно-интегрированного управления реализацией стратегии роста компании.

Концепция системно-интегрированного управления базируется на интеграции научных основ стоимостно-ориентированного менеджмента (VBM) и концепции сбалансированной системы показателей (BSC). Концепция VBM 
определяет увеличение стоимости компании как доминантный критерий управленческих решений, обеспечивающих процесс реализации стратегии роста, и составляет основу идентификации ключевых драйверов роста организации. Концепция BSC решает методологические проблемы систематизации и сбалансированности ключевых драйверов роста (финансовых и нефинансовых) по существенным с точки зрения реализации стратегии проекциям. Системность концепции обусловлена структурной целостностью и взаимосвязью ее теоретико-методологических положений, представленных в виде модулей - элементов системы управления реализацией стратегии роста организации [8].

Вначале рассмотрим классические принципы стратегического менеджмента, преобразованные для использования при реализации стратегии роста организации на базе концееции системно-интегрированного управления.

Принци комплексности проявляется в трех аспектах.

Во-первых, он предполагает, что управление реализацией стратегии роста связано со всеми видами деятельности компании: операционной, инвестиционной, финансовой. Увеличение стоимости организации базируется на управлении активами (или инвестированным капиталом) и операционной эффективности, которые определяют рентабельность инвестированного капитала, и финансовой политике, которая определяет структуру и средневзвешенную стоимость капитала. Соответственно, величина и структура инвестированного капитала (IC), индикатора роста, - это область принятия инвестиционных решений; рентабельность инвестированного капитала (ROIC), характеризующая эффективность использования инвестиционных ресурсов, задает сферу операционных решений и операционной эффективности; средневзвешенная стоимость капитала (WCC), показатель стоимости и структуры инвестиционных ресурсов, определяет контур принятия финансовых решений. При этом в отличие от научных работ предыдущих исследователей (в период развития концепции стоимостного менеджмента, основанного на денежных потоках), ключевыми идеями подходов которых являлись оценка инвестиционной привлекательности проектов, финансовых потоков, стоимости компании, в представленной научной системе особое место нами отводится операционной деятельности, ее эффективности и результативности в процессе реализации стратегии роста. Фундамент основной деятельности компании составляет экономика, поскольку именно экономические решения, направленные на эффективность использования реальных ресурсов, в большей степени влияют на финансовое благополучие компании, ее инвестиционный потенциал и потенциал экономического роста. Кроме того, операционная, инвестиционная и финансовая деятельности тесно связаны друг с другом, а операционная деятельность определяет как инвестиции (инвестиционные критерии), так и финансовые параметры.

Во-вторых, принцип комплексности подразумевает взаимосвязанное использование совокупности инструментов стратегического менеджмента, инкорпорированных в единый механизм и используемых согласованно для достижения главной цели.

В-третьих, предполагает многофакторное исследование процесса управления реализацией стратегии роста организации. 


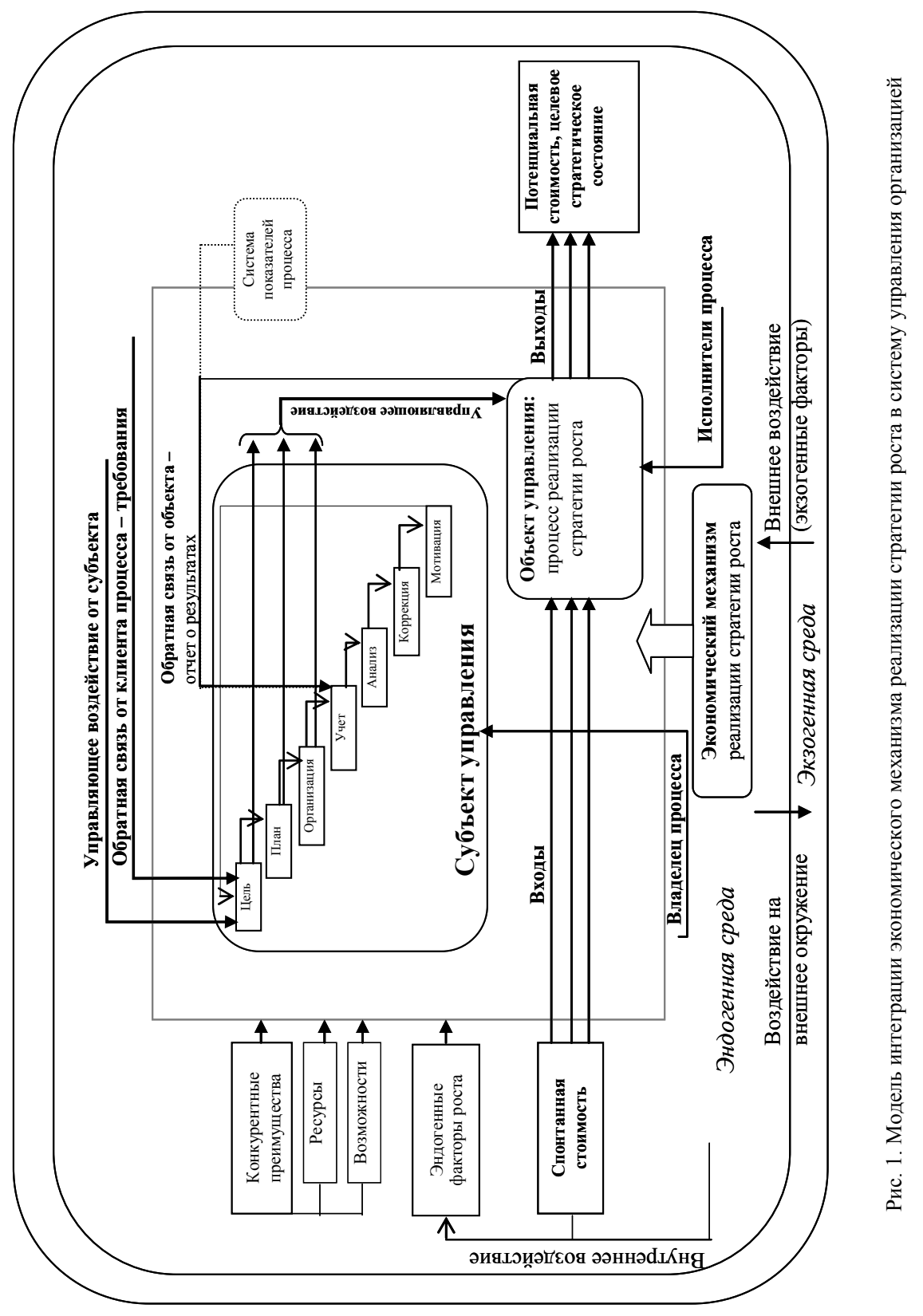


Принцип интеграции проявляется также в трех аспектах.

Во-первых, авторская концепция системно-интегрированного управления реализацией стратегии предполагает интеграцию компании как системы с экзогенной средой посредством исследования влияющих факторов, взаимосвязей. В этом плане макро- и микросреда компании рассматривается как социально-экономическая система.

Во-вторых, принцип интеграции предполагает консолидацию подсистем управления на основе бизнес-процессов.

В-третьих, авторская концепция основывается на методологическом положении об интеграции экономического механизма реализации стратегии роста в систему управления компанией (рис. 1).

Процесс управления реализацией стратегии роста подчинен действию определенного экономического механизма. Как показано на рисунке, экономический механизм реализации стратегии роста организации является составной частью общей системы управления компанией.

Экономический механизм приводит в действие эту систему посредством определенного набора управленческого инструментария для достижения экономического роста, тем самым обеспечивается переход компании к её целевому стратегическому состоянию.

Принци системности предполагает формирование целостного представления об экономическом механизме реализации стратегии роста и выявление многообразных связей между его компонентами, образованных на основе их подчинения цели экономического роста.

Принцип непрерывности означает выполнение необходимых процедур и принятие решений на всех этапах управления реализацией стратегии роста.

Принцип динамичности проявляется в периодической корректировке стратегии роста компании в процессе ее реализации и способов достижения стратегических целей в случае существенных изменений условий экзогенной среды. Несмотря на то, что стратегия - это долгосрочный документ, разрабатывается на длительный период, необходима ее постоянная актуализация на основе данных отчета о реализации стратегии, включающего в том числе информацию об изменениях экзогенной среды. Воздействие внешней среды учитывается с помощью экзогенных факторов, открывающих новые возможности роста или новые угрозы. В целом динамический аспект концепции системно-интегрированного управления реализацией стратегии роста обеспечивает конкурентоспособность компании.

Принцип сбалансированности рассмотрен нами с двух позиций.

Во-первых, он предусматривает соблюдение в процессе достижения главной стратегической цели равновесных пропорций по всем аспектам реализации стратегии роста (включая подцели по стратегическим перспективам сбалансированной системы показателей (BSC), ключевые драйверы роста) с целью уравновешивания интересов стейкхолдеров. Этот баланс достигается посредством установления пограничных значений ключевых показателей деятельности по основным стратегическим перспективам BSC и требует постоянного контроля динамики их значений во избежание дисбаланса.

Во-вторых, принцип сбалансированности предполагает рациональное распределение плана по созданию стоимости между бизнес-единицами, под- 
разделениями, дифференцированной по продуктам, находящимся на различных стадиях жизненного цикла (по Бостонской матрице), для целей максимизации общей стоимости компании.

Принцип иерархичности предполагает выделение стратегического, тактического и оперативного уровней внутрифирменного управления реализацией стратегии роста и создание вертикальных связей между уровнями управления посредством подчинения низших уровней высшим, поскольку стратегия осуществляется через тактику и оперативные действия.

Принцип делегирования предполагает рациональное распределение полномочий и ответственности за реализацию стратегии роста между сотрудниками компании по уровням и элементам внутрифирменного управления.

Принци измеримости подразумевает наличие системы оценки эффективности и результативности управления реализацией стратегии роста компании, включающей количественные и качественные показатели.

Принцип соответствия означает согласованность политик, регламентов, положений, процедур, организационной структуры, бизнес-процессов, бюджетов, планов деятельности компании с ее стратегией развития.

Принци универсальности подразумевает общность концептуальнометодологических положений, содержащих сущностные характеристики системно-интегрированного управления, несмотря на обширную типологию компаний.

Принцип специализации предполагает, что практическая реализация концепции системно-интегрированного управления стратегическими изменениями растущей организации требует применения индивидуального подхода к менеджменту конкретной компании.

Далее рассмотрим специфические принципы, разработанные в соответствии с авторской концепцией системно-интегрированного управления реализацией стратегии роста организации.

Принцип ограничения экономического роста критерием увеличения стоимости компании. Увеличение стоимости компании становится главным критерием эффективности экономического роста, который определяет стратегические, тактические и оперативные управленческие решения, направленные на его достижение. Ввиду того, что экономический рост не всегда приводит к росту стоимости, считаем целесообразным ввести ограничение на темпы роста продаж и активов (инвестированного капитала) компании в виде порогового значения рентабельности инвестированного капитала (ROIC), которая должна превышать стоимость его обслуживания (WACC), иными словами, спрэд экономической добавленной стоимости (spread EVA ${ }^{1}$ ) в целом по компании должен быть положительным.

Принцип дифференциаци моделей экономического роста в зависимости от приоритетов и спектра факторов управления. Модели экономического роста предлагается дифференцировать по его ключевым комплексным индикаторам (объем продаж, величина инвестированного капитала, производительность инвестированного капитала, рентабельность продаж, сред-

\footnotetext{
${ }^{1}$ Разработана и зарегистрирована как торговая марка консалтинговой компанией Stern Stewart \&
} 
невзвешенная стоимость капитала, значение финансового рычага) и изменчивости параметров деловой активности компании.

Принцип первостепенной роли формирования и использования инвестиционного потенциала в реализации стратегии роста компании, который является ключевым интегрирующим элементом системы функциональных возможностей организации в процессе реализация стратегии роста, непосредственно обусловливает экономический рост и способствует созданию будущих конкурентных преимуществ компании. Взаимосвязь компонентов триады «инвестиционный потенциал - экономический рост - стоимость компании» определяет траекторию развития организации.

Принцип декомпозиции главной цели стратегии роста предполагает трансляцию главной стратегической цели эффективного экономического роста на все подчиненные уровни управления, их бизнес-процессы и оперативные решения посредством создания адекватного экономического механизма.

Принцип гармонизации подразумевает, что все компоненты (инструменты) экономического механизма должны быть адаптированы к современной парадигме стоимостно-ориентированного менеджмента (VBM) и направлены на достижение цели экономического роста посредством воздействия на определяющие его ключевые драйверы по четырем стратегическим перспективам $\mathrm{BSC}$ для обеспечения эффективной и результативной реализации стратегии роста.

Принцип формирования стратегического стоимостно-ориентированного мышления означает осознание стратегических целей деятельности компании и способов их достижения всеми сотрудниками. Он подчеркивает важность вовлеченности всех сотрудников компании в процесс реализации стратегии роста посредством обучения, оценки, мотивации и информирования персонала; доведения стратегии развития компании до каждого сотрудника; обучение персонала с целью формирования стратегического мышления, в основе которого лежит восприятие сотрудниками факторов роста, необходимое для обеспечения принятия эффективных управленческих решений с позиций реализации стратегии роста; использование системы оценки и мотивации персонала, включающей показатели реализации стратегии роста (исходя из принципа приоритетности цели увеличения стоимости, менеджмент должен отвечать за показатели, связанные не только с текущей деятельностью, но и с будущими стратегическими позициями компании).

Принцип мониторинга реализации стратегии для целей оценки эффективности и степени достижения стратегических целей, а также для обоснования целесообразности актуализации стратегии в связи с существенным изменением экзогенных факторов роста. Мониторинг реализации стратегии, по нашему мнению, должен включать анализ динамики экзогенных и эндогенных факторов, определяющих темпы роста организации, степени их влияния на реализацию стратегии роста (для последующей возможной корректировки управляющего воздействия и(или) инициирования внесения изменений в стратегию развития), целей, задач, процессов, результатов на основе специальной системы индикаторов эффективности и результативности реализации стратегии роста компании, включающей финансовые и нефинансовые пока- 
затели, оценку стоимости компании. Такой системой в контексте концепции системно-интегрированного управления является BSC.

Принцип проактивности. В отличие от реактивного подхода к управлению, согласно которому стратегия фирмы адаптируется к ее специфической внешней среде, проактивность предполагает опережающее формирование и использование инвестиционного потенциала отечественных организаций по сравнению с зарубежными компаниями-аналогами, инициирование ими изменений в экзогенной среде, активное создание уникальных продуктов, являющихся основой их конкурентных преимуществ.

Использование методологии системно-интегрированного управления реализации стратегии роста организации является перспективным направлением развития теории и практики стратегического управления. Научные положения о принциипах реализации стратегии роста расширяют представление об эффективных способах достижения стратегических иелей организации. Представленная совокупность принципов определяет методологию обоснования управленческих решений в области реализации стратегии роста организации, создает научную основу для модернизащии сущеествующих моделей экономического роста (на основе результатов исследования взаимосвязи экономического роста и стоимости организаџии), традиционной модели оценки безубыточности и классических методов иенообразования в рамках стоимостно-ориентированного менеджмента; формирования экономического механизма реализации стратегии роста $и$ его имплементации в систему управления организацией, в которой стратегические цуели организации соотнесены с критериями эффективного роста, факторами и показателями их достижения, а также комплекса практических рекомендаций по обоснованию темпов, способов, моделей роста организации в зависимости от ее инвестиционного потенциила, текущего и ичелевого стратегического состояния.

Использование отмеченных принципов в деятельности отечественных компаний позволит обеспечить эффективный экономический рост на микро-, мезо- и макроэкономическом уровне и высокую степень достижения стратегических целей в соответствии с инновационным сценарием долгосрочного социально-экономического развития России.

\section{Лumepamypa}

1. Клейнер Г.Б. Системная парадигма и теория предприятия // Вопр. экономики. 2002. № 10. C. 47-69.

2. Коупленд T., Колер Т., Мурин Д. Стоимость компаний: оценка и управление: пер. с англ. Н.Н. Барышниковой. 3-е изд. М.: Олимп-бизнес, 2008. 554 с.

3. Малиновская О.В., Скобелева И.П. Управление стоимостью компании - новый этап развития стратегического управления на транспорте // Журнал Университета водных коммуникаций. 2009. Вып. 1. С. 136-147.

4. Скобелева И.П., Рыбин В.Н. Потенциал концепции ценностно-ориентированного (стоимостного) менеджмента // Вестн. ИНЖЕКОНа. Серия «Экономика». 2011. Вып. 1(44). С. 17-22.

5. Тарасов A.K. Принципы стратегического управления в теории принятия решений / под ред. В.А. Тихомирова. М.: Финансы и статистика, 2012. 143 с.

6. Тейлор Ф.У. Менеджмент: пер. с англ. А.И. Зак. М.: Изд-во стандартов, 1992. 137 с.

7. Файоль А. Общее и промышленное управление: пер. с фр. М.: Изд-во стандартов, 1992. $111 \mathrm{c}$. 
8. Палкина E.C. Современная концепция реализации стратегии роста транспортной организации // Актуальные вопросы проектного и процессного менеджмента: тр. Всерос. науч.практ. конф. ученых транспортных вузов и представителей академической науки. 10-12 декабря 2014 г. Хабаровск: Изд-во ДВГУПС, 2014. С. 279-284.

E.S. Palkina. Department of Transport Economics, Petersburg State Transport University, St. Petersburg, Russia. E-mail: elena_palkina@hotmail.com

\section{METHODOLOGICAL PRINCIPLES OF MANAGING THE IMPLEMENTATION OF A COMPANY'S GROWTH STRATEGY}

Keywords: Concept of integrated system management; Methodology of implementing a strategy; Principles of management; Growth strategy; Economic growth

This paper appears particularly relevant in the context of the transition of the Russian economy to the economic growth model. Its relevance is justified by the fact that it investigates ways of improving the effectiveness of economic entities through extensive use of a new economic mechanism for successful implementation of the growth strategy. This paper contains corresponding methodological principles of managing the implementation of a company's growth strategy.

The studies conducted by Russian and foreign scientists show that the existing background theoretical provisions are either applicable primarily to the elaboration of a company's strategy or are of general nature, that is to say, cover strategic management in general. At the same time, some issues still have not been properly studied. These include the influence of a chosen strategy on the specifics and priorities of managing the implementation of a company's development strategy, the correlation of organizations' growth objectives with other strategic objectives have not been reflected in an appreciable way and are not summarized in the scientific literature.

The proposed principles are based on the scientific provisions of the author's concept of scientific integrated system management, which are presented in detail in the author's paper "The modern concept of the implementation of a transport organization's growth strategy". These principles are divided into two groups. The first group comprises the classical principles of strategic management, modified for the implementation of the growth strategy of an organization, the second one is composed of specific principles elaborated in accordance with the author's concept of integrated system management of the organization's growth strategy implementation.

The classical principles are comprehensiveness, integration, systematicity, consistency, responsiveness, centeredness, hierarchy, delegation, measurability, relevance, flexibility, specialization.

The group of specific principles comprises the principle of restraining the economic growth by the criterion of increasing value of a company; the principle of differentiation of economic growth models depending on the priorities and the range of management factors; the principle of paramount importance of the formation and use of investment potential for the purpose of implementing a company's growth strategy; the principle of decomposition of the main objective in the framework of the growth strategy; the principle of harmonization; the principle of developing strategic value-based thinking, the principle of monitoring the implementation of the, the principle of proactivity.

The outlined set of principles pre-determines the methodology of justifying managerial decisions and ensures scientific basis for the formation of an economic mechanism of the implementation of the growth strategy and the synthesis of its constituent management tools in the management system of an organization. Introduction of these principles to Russian companies will provide effective economic growth at the micro, meso- and macroeconomic levels and high performance at achieving strategic objectives within an innovative scenario of the long-term socio-economic development of Russia.

\section{References}

1. Kleyner G.B. Sistemnaya paradigma i teoriya predpriyatiya [System paradigm and the theory of enterprise]. Voprosy ekonomiki, 2002, no. 10, pp. 47 - 69.

2. Copeland T., Koller T., Murrin J. Valuation: Measuring and Managing the Value of Companies. 3d edn., New York, John Wiley \& Sons Inc. Publ., 2000. 512 p. (Russ. ed.: Baryshnikova N.N. Stoimost' kompaniy: otsenka i upravleniye. Moscow, Olimp - biznes Publ., 2008. 554 p.

3. Malinovskaya O.V., Skobeleva I.P. Upravleniye stoimost'yu kompanii - novyy etap razvitiya strategicheskogo upravleniya na transporte [Value-based management is a new stage of the development of strategic transport management]. Zhurnal universiteta vodnykh kommunikatsiy, 2009, issue 1, pp. 136-147. 
4. Skobeleva I.P. Potentsial kontseptsii tsennostno-oriyentirovannogo (stoimostnogo) menedzhmenta [Prospects for the concept of value-based management]. Vestnik INZHEKONa. Seriya ekonomika, issue 1(44), 2011, pp. 17-22.

5. Tarasov A.K. Printsipy strategicheskogo upravleniya v teorii prinyatiya resheniy [The Principles of Strategic Management in the Theory of Decision Making]. Moscow, Finansy i statistika Publ., 2012. 143 p.

6. Taylor F.W.. Management (Russ. ed.: Zak A.I. Menedzhment. Moscow, Izd-vo Standartov, 1992. 137 p.).

7. Fayol H. General and Industrial Management. LEEE Publ., 1984. 112 p. (Russ. ed.: Kuritsyn A.N. Obshcheye i promyshlennoye upravleniye. Moscow, Izd-vo Standartov, 1992. 111 p.).

8. Palkina E.S. Sovremennaya kontseptsiya realizatsii strategii rosta transportnoy organizatsii. Trudy Vserossiyskoy nauch. - prakticheskoy konf. uchenykh transportnykh vuzov i predstaviteley akademicheskoy nauki “Aktual'nyye voprosy proyektnogo i protsessnogo menedzhmenta”[Proc. AllRussia Sci. and Prac. Conf. of Sci. of Trans. Inst. and Rep. of Ac. Sci. "Actual Problems of Project and Process Management”]. Khabarovsk, Far East St. Trans. Uni. Publ., 2014, pp. 279-284. (In Russian).

Поступила в редакцию 21.05.2015

Received June 21.05. 2015

\section{For referencing:}

Palkina E.S. Metodologicheskiye printsipy upravleniya realizatsiyey strategii rosta kompanii [Methodological principles of managing the implementation of a company's growth strategy]. Vestnik Tomskogo gosudarstvennogo universiteta. Ekonomika - Tomsk State University Journal of Economics, 2015, no. 2 (30), pp. 78-86. 